\title{
Promising Antitumor Activity of a Novel Quinoline Derivative, TAS-103, against Fresh Clinical Specimens of Eight Types of Tumors Measured by Flow Cytometric DNA Analysis
}

\author{
Shuichi Fujimoto \\ Division of Chemotherapy, Chiba Cancer Center Research Institute; 666-2 Nitona-cho, Chuoh-ku, Chiba 260-8717, \\ Japan. Received May 22, 2007; accepted July 17, 2007; published online July 18, 2007
}

TAS-103, 6-[[2-(dimethylamino)ethyl]amino]-3-hydroxy-7H-indeno-[2,1-c]quinolin-7-one dihydrochloride, is a dual topoisomerases I and II inhibitor. Antitumor activities of TAS-103 against fresh surgical specimens resected from 525 patients (32 types of tumors) were examined by flow cytometric (FCM) analysis of DNA integrity of tumor cells, and compared with those of five other investigational new drugs and 31 clinically available anticancer agents. Concentrations of clinically available anticancer agents were set at one-tenth of the peak plasma concentration (PPC) of the clinically recommended doses. On the other hand, since PPCs of investigational new drugs in humans were frequently unknown, these were estimated by a method that determines the theoretically achievable concentration in body fluid (TAC method). Correlations between TAC and PPC were examined for 16 clinically available anticancer agents, and it was found that TAC at $7 \mathrm{n}$ (the modified Fibonacci's dose-escalation scheme) of 14 drugs corresponded well with each one-tenth of PPC. By defining a 30\% or more reduction in the integrated diploid peak as effective and a $60 \%$ or more reduction as definitely effective, TAS- 103 at $5 \mu \mathrm{g} / \mathrm{ml}(7 \mathrm{n})$ showed significantly higher effective rates and definitely effective rates than those of all other investigational new drugs, as well as almost all clinically available anticancer agents, against various malignancies, including nonsmall cell lung cancer, brain tumor and renal cancer. These results strongly suggest that TAS-103 will be expected to show excellent antitumor activities against a wide range of human tumors.

Key words TAS-103; new anticancer agent; clinical specimen; flow cytometry; antitumor activity in vitro

A novel quinoline derivative, TAS-103 (Fig. 1), has many attractive biological functions: i) it inhibits both topoisomerase (topo) I and topo II; ii) it stabilizes both topo I- and topo II-DNA cleavable complexes; iii) it shows potent cytotoxic effects in vitro; iv) it shows high antitumor activities against subcutaneously-implanted murine and human tumors in vivo, as well as various lung-metastatic murine tumors. ${ }^{1)}$ However, it is unclear whether TAS-103 will show the similar level of activity against tumors in patients. In this setting, the chemosensitivity test is expected to show its potential for predicting activity of anticancer agents against human tumors.

Various in vitro drug sensitivity tests have been used to assay the responsiveness of tumors to anticancer agents. ${ }^{2-7)}$ Among various techniques, the colony-forming assay may be the most widely applied in vitro assay for clinical use. ${ }^{8)}$ In a large study of prospective trials using colony-forming assay, it was shown that true-positive rate was $60 \%$ and true-negative rate was $85 \%$ based on clinical response. ${ }^{9}$ Although this assay seems to be reliable for predicting the clinical response to chemotherapies, it is time- and cost-consuming, laborintensive, and suffers from a low success rate. ${ }^{10)}$ In addition, this assay requires preparations of a single-cell suspension, which renders considerable damage to the tumor cells.

We have used direct in vitro measurements of apoptosis as a chemosensitivity test. Two different methods have been employed; morphological examinations of the nuclear damage, such as the chromatin condensation or degradation, ${ }^{5)}$ and flow cytometric (FCM) analysis of DNA integrity which shows apoptosis as the sub-G1 population. ${ }^{11)}$ The FCM assay

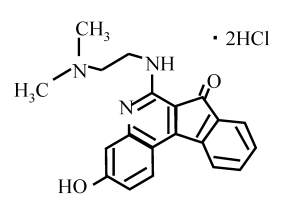

TAS-103

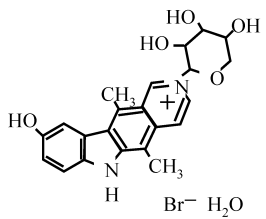

SUN-4599

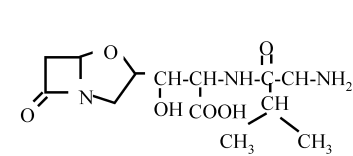

$69 \mathrm{~A}$

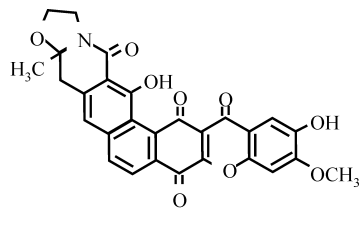

4181

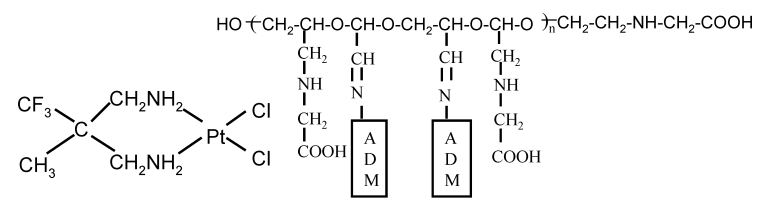

P-1301

ADM-OXD

Fig. 1. Structures of Investigational New Drugs 
is a simple and reproducible method for detecting apoptosis, and has been widely used in basic laboratory studies. ${ }^{12,13)}$ One of the advantages of the FCM assay is that the singlecell suspension is theoretically unnecessary at the initial stage of the assay, which would contribute to a high success rate and high predictive accuracy. ${ }^{11)}$ Predictability of clinical responses by the morphological method was shown to have the overall accuracy of $94 \%$ in ovarian cancer patients, ${ }^{14)}$ and that by the FCM assay was $82 \%$ in brain tumors. ${ }^{15)}$ In addition, favorable increase in survival time of patients with glioblastoma multiforme was observed by treatment with anticancer agents selected by the FCM assay. ${ }^{16)}$

Determination of the drug concentration employed in in vitro chemosensitivity test is another problem. One-tenth of the peak plasma concentration (PPC) has been commonly used as a standard concentration of anticancer drugs for in vitro chemosensitivity test of human tumors. ${ }^{17,18)}$ However, since the PPCs of the investigational new drugs in humans are frequently unknown, any method for predicting the PPCs of these drugs clearly needs to be developed. As a candidate, the theoretically achievable concentration (TAC) method ${ }^{19)}$ was examined and confirmed to be applicable to this purpose.

In the present study, with the FCM assay and the TAC method, the antitumor activity of TAS-103 was examined against various surgical specimens and compared with those of other investigational new drugs, as well as those of representative anticancer agents currently in clinical use. As a result, TAS-103 was shown to have the highest antitumor activities against a variety of human tumors among almost all drugs examined.

\section{MATERIALS AND METHODS}

Surgical Specimens The chemosensitivity tests were carried out with fresh surgical specimens resected from 525 patients (32 types of tumors) at Chiba Cancer Center Hospital and Chiba University Hospital from November 1994 to December 2005. Assay results for main eight types of tumors (which have large number of samples) are shown in the present study. These were non-small cell lung cancer $(n=236)$, brain tumor $(n=101)$, bone and soft tissue sarcomas $(n=68)$, renal cancer $(n=37)$, uterine tumor $(n=21)$, breast cancer $(n=15)$, small cell lung cancer $(n=13)$ and ovarian cancer $(n=10)$. The chemosensitivity tests were performed by request of physicians in order to get informations that assist them in considering the clinical protocol for the individual patients. Informed consent was obtained, by physicians, from all patients with respect to performing the chemosensitivity test by using their resected tumor specimens.

Drugs and Concentrations The tests have been done with 31 clinically available anticancer agents and six investigational new drugs, which had been successively provided (Table 1). Concentrations of clinically available anticancer agents were set at one-tenth of the PPC of the clinically recommended doses. ${ }^{20-35)}$ To evaluate the pro-drugs adequately, the in vivo activated forms, 4-hydroperoxycyclophosphamide, 4-hydroperoxyifosfamide and 7-ethyl-10-hydroxycamptothecin (SN-38), were used for cyclophosphamide, ifosfamide and irinotecan, respectively.

Since the PPC of the investigational new drugs, including
TAS-103, in humans was frequently unknown, the concentration of these agents was estimated by a method that determined the theoretically achievable concentration in body fluid (TAC method) advanced by Schabel et al. ${ }^{19)}$ For example, i) the highest nonlethal dose of TAS-103 in mice given intravenously (i.v.) by a single injection was $67 \mathrm{mg} / \mathrm{kg}$, ${ }^{1}$ ii) converting this dose at $\mathrm{mg} / \mathrm{m}^{2}$ level by multiplying a $K_{\mathrm{m}}$ factor $^{36)}$ of 3 (for mice), $201 \mathrm{mg} / \mathrm{m}^{2}$, iii) one-tenth of this dose has generally been employed as a starting dose (n) in the clinical phase I study, ${ }^{37)} 20 \mathrm{mg} / \mathrm{m}^{2}$, iv) converting this dose at $\mathrm{mg} / \mathrm{kg}$ level by dividing with a $K_{\mathrm{m}}$ factor of 37 (for man), $0.54 \mathrm{mg} / \mathrm{kg}, \mathrm{v})$ the TAC could be estimated by multiplying a factor of 1.3 , since the body fluid is approximately $80 \%{ }^{19}$; $0.71 \mu \mathrm{g} / \mathrm{ml}$, and vi) assuming the maximum tolerated dose (MTD) in man to be $7 \mathrm{n}$ to $9 \mathrm{n}$ at the modified Fibonacci's dose-escalation scheme, ${ }^{37)}$ approximately $5 \mu \mathrm{g} / \mathrm{ml}$. In the present study, antitumor activity of TAS-103 was tested at both $5 \mu \mathrm{g} / \mathrm{ml}(7 \mathrm{n})$ and $0.5 \mu \mathrm{g} / \mathrm{ml}(0.7 \mathrm{n})$. Other investigational new drugs were tested for antitumor activity at $7 \mathrm{n}$. These drugs were SUN-4599, P-1301, ADM-OXD (adriamycinoxydextrane complex, adriamycin 28.3\%), 69A and 4181 (Fig. 1). The highest nonlethal doses of these agents in mice (which were obtained from individual pharmaceutical companies) are shown in Table 1.

Determination of MTD in Mice Determination of the highest nonlethal dose in mice of 16 clinically available anticancer agents had been carried out at Cancer Chemotherapy Center, Japanese Foundation for Cancer Research. This study had been performed according to the guidelines of the Cancer Chemotherapy Center Experimental Animal Care and Use Committee, and indeed conducted in accordance with the guidelines. Adult $\mathrm{C} 57 \mathrm{BL} / 6 \times \mathrm{DBA} / 2 \mathrm{~F}_{1}\left(\mathrm{BDF}_{1}\right)$ mice of either sex, 8-12 weeks old, were used in these studies. All the mice were supplied by the Division of Cancer Treatment, National Cancer Institute, Bethesda, Md. U.S.A. The animals were given food and water ad libitum. All drugs, except melphalan, were dissolved in physiological saline, diluted by a factor of 1.25 at several dose levels, and administered i.v. into a group of $10 \mathrm{mice} / \mathrm{dose}$ as a single injection or 3 injections at $4-d$ interval $(q 4 d x 3)$. Melphalan was suspended in $0.5 \%$ carboxymethylcellulose in physiological saline and given i.p. by a single injection. All animals were observed for $45 \mathrm{~d}$ after the last administration of drugs and the mortality was recorded.

Chemosensitivity Testing Surgically resected tumor tissues were immediately minced and suspended in RPMI 1640. The micro-cell aggregate suspension was passed through a sterilized mesh several times to remove fibrous connective tissue, and centrifuged at $1000 \mathrm{rpm}$ for $5 \mathrm{~min}$ to eliminate fatty tissues and necrotic portions. An aliquot of the cell suspension was incubated with each agent dissolved in RPMI 1640 supplemented with $10 \%$ fetal calf serum at $37^{\circ} \mathrm{C}$ in $5 \% \mathrm{CO}_{2}$ for $8 \mathrm{~h}$, and then cultured in fresh drug-free RPMI 1640 supplemented with $10 \%$ fetal calf serum and $100 \mu \mathrm{g} / \mathrm{ml}$ of kanamycin for $72 \mathrm{~h}$. To visualize the morphological changes of drug-induced cell death, cells were fixed with $100 \%$ methanol and stained with Giemsa on a slide glass. ${ }^{5)}$ Two hundred nuclei per slide were observed using the high-power field of a light microscope. Degenerative changes noted in the nuclei, including chromatin degradation or condensation, were judged as markers of apoptosis, and counted 
Table 1. In Vitro Concentration and Highest Nonlethal Dose in Mice of Clinically Available Anticancer Agents and Investigational New Drugs

\begin{tabular}{|c|c|c|c|c|c|}
\hline Agents & Abbreviation & $\begin{array}{c}\left.0.1 \mathrm{PPC}^{a}\right) \\
(\mu \mathrm{g} / \mathrm{ml})\end{array}$ & Ref. & $\begin{array}{c}\mathrm{TAC}^{b)} \\
(\mu \mathrm{g} / \mathrm{ml})\end{array}$ & $\begin{array}{l}\mathrm{HNLD}^{c)} \\
(\mathrm{mg} / \mathrm{kg} / \mathrm{d})\end{array}$ \\
\hline \multicolumn{6}{|l|}{ Topoisomerase inhibitors } \\
\hline Aclarubicin & ACR & 0.6 & 34 & & \\
\hline Actinomycin D & $\mathrm{ACD}$ & 0.01 & 20 & & \\
\hline Adriamycin & $\mathrm{ADM}$ & 0.3 & 20 & 0.36 & $5.1(\mathrm{q} 4 \mathrm{dx} 3)^{d)}$ \\
\hline Daunomycin & DM & 0.6 & 20 & 0.93 & $13.3(\mathrm{q} 4 \mathrm{dx} 3)$ \\
\hline Epirubicin & EPI & 0.4 & 33 & & \\
\hline Etoposide & VP-16 & 3 & 20 & 1.8 & $25(q 4 d x 3)$ \\
\hline Irinotecan & SN-38 & 0.02 & 35 & & \\
\hline Mitoxantrone & MIT & 0.06 & 24 & & \\
\hline Pirarubicin & THP & 0.3 & 32 & & \\
\hline \multicolumn{6}{|l|}{ Antitumor antibiotics } \\
\hline Bleomycin & BLM & 1 & 20 & 4.5 & $64(q 4 d x 3)$ \\
\hline Mitomycin C & $\mathrm{MMC}$ & 0.2 & 20 & 0.23 & $3.3(\mathrm{q} 4 \mathrm{dx} 3)$ \\
\hline Neocarzinostatin & NCS & 0.15 & 31 & & \\
\hline Peplomycin & PEP & 0.5 & 22 & 0.70 & $10(q 4 d x 3)$ \\
\hline \multicolumn{6}{|l|}{ Antimetabolites } \\
\hline Cytosine arabinoside & Ara-C & 4 & 20 & & \\
\hline 5-Fluorouracil & 5-FU & 10 & 20 & 11 & 164 (1 shot) \\
\hline Methotrexate & MTX & 3 & 20 & 2.4 & $34(q 4 d \times 3)$ \\
\hline Thioinosine & 6-MPR & 3 & 20 & & \\
\hline \multicolumn{6}{|l|}{ Antimicrotuble agents } \\
\hline Paclitaxel & TAX & 0.6 & 30 & & \\
\hline Vinblastine & VLB & 0.1 & 20 & 0.62 & $8.9(\mathrm{q} 4 \mathrm{dx} 3)$ \\
\hline Vincristine & VCR & 0.1 & 20 & 0.13 & $1.9(\mathrm{q} 4 \mathrm{dx} 3)$ \\
\hline Vindesine & VDS & 0.1 & 20 & 0.19 & $2.7(\mathrm{q} 4 \mathrm{dx} 3)$ \\
\hline \multicolumn{6}{|l|}{ Alkylating agents } \\
\hline Buslphan & BUS & 0.8 & 25 & & \\
\hline Carboplatin & JM-8 & 4 & 29 & & \\
\hline Carboquone & CQ & 0.1 & 21 & 0.11 & 1.6 (1 shot) \\
\hline Cisplatin & CDDP & 0.5 & 20 & 0.34 & $4.8(\mathrm{q} 4 \mathrm{~d} \times 3)$ \\
\hline Cyclophosphamide & CPM & 1 & 26 & & \\
\hline Ifosfamide & IFOS & 1 & 27 & & \\
\hline Melphalan & MPL & 0.5 & 20 & 0.70 & 10 (1 shot) \\
\hline Nimustine & $\mathrm{ACNU}$ & 2 & 23 & 2.2 & 32 (1 shot) \\
\hline Ranimustine & MCNU & 2 & 42 & 2.2 & 32 (1 shot) \\
\hline Thio-TEPA & TESPA & 2 & 28 & & \\
\hline \multicolumn{6}{|l|}{ Investigational new drugs } \\
\hline 4181 & 4181 & & & 1 & 50 (1 shot) \\
\hline $69 \mathrm{~A}$ & $69 \mathrm{~A}$ & & & 0.3 & 15 (1 shot) \\
\hline ADM-oxydextran & ADM-OXD & & & 3.2 & 152 (1 shot) \\
\hline P-1301 & P-13 & & & 0.5 & 8 (1 shot) \\
\hline SUN-4599 & SUN & & & 5 & 18 (1 shot) \\
\hline TAS-103 & TAS & & & $5,0.5$ & 67 (1 shot) \\
\hline
\end{tabular}

a) PPC: peak plasma concentration. b) TAC: theoretically achievable concentration in the body fluid and the concentration at $7 \mathrm{n}$ in the modified Fibonacci's dose-escalation scheme was shown. c) HNLD: highest nonlethal dose in $\mathrm{BDF}_{1}$ mice and TAC was calculated based on this dose. $d$ ) q4dx3:3 injections at 4-d interval.

to compare with non-treated controls. This morphological study showed that the average percentages of tumor cells in the preparations were consistently over 95 . In addition to the morphological assay, the FCM analysis of propidium iodidestained nuclei was performed, by which apoptotic cells were quantified as the proportion of the sub- $\mathrm{G}_{1}$ population. For the FCM analysis, tumor specimens were prepared in the same way as for the morphological assay, and were mixed with phosphate buffered-saline $(\mathrm{pH} 7.2) / 0.1 \%$ Triton $\mathrm{X}-100 / 0.1$ $\mathrm{mg} / \mathrm{ml}$ RNase (Sigma, St. Louis, MO, U.S.A.) $/ 0.01 \%$ sodium azide for $15 \mathrm{~min}$, and then with $100 \mu \mathrm{g} / \mathrm{ml}$ propidium iodide (Sigma, St. Louis, MO, U.S.A.) for $15 \mathrm{~min}$. Isolated nuclei were analyzed with a flow cytometer (FACScan, Becton Dickinson, Mountain View, CA, U.S.A.). Apoptotic nuclei shifted to the hypodiploid (sub- $\mathrm{G}_{1}$ ) area and the effectiveness of drugs was judged by the reciprocal reduction in the integrated diploid peak compared with that of untreated control cells. A good correlation between increase in the sub- $\mathrm{G}_{1}$ peak and decrease in the $\mathrm{G}_{0} / \mathrm{G}_{1}$ peak was observed in the treatment of the adenocarcinoma of the lung with 37 anticancer agents. ${ }^{38)}$ More than $30 \%$ reduction in the integrated diploid peak (less than $70 \%$ in $\mathrm{T} / \mathrm{C}$ ) was judged to be positive.

Definition of Activity More than 30\% reduction in the integrated diploid peak ( $70 \%$ cut-off) was defined as effective, and more than $60 \%$ reduction ( $40 \%$ cut-off) was defined as definitely effective. The $70 \%$ cut-off correlated with a more than 50\% inhibition of P388 and L1210 cell growth in vitro, and the $40 \%$ cut-off correlated with a complete inhibition of the cell growth. ${ }^{39)}$ In addition, when rats were inoculated intracranially with $9 \mathrm{~L}$ rat brain tumors and were treated with drugs which were effective ( $70 \%$ cut-off) against these tumor cells in vitro, growth retardation of inoculated brain tumors and prolonged survival of inoculated rats were ob- 
served. ${ }^{11)}$ Furthermore, when the $70 \%$ cut-off was applied for the antitumor activity of eight anticancer drugs, which are active clinically, ${ }^{40}$ against 141 fresh specimens of non-small cell lung cancer, seven drugs showed a good correlation between the clinical activity and in vitro activity. ${ }^{39)}$

Statistical Analysis Experimental results were analyzed for significance by Fisher's exact test for the morphological degenerative changes in the nuclei and FCM assay. A $p$-value of 0.05 or less was regarded as significant.

\section{RESULTS}

Correlation between Drug Concentrations Determined by PPC and TAC Methods Since the concentrations of clinically available anticancer agents were determined based on the PPC method and those of investigational new drugs on the TAC method, it became a matter of concern whether both concentrations corresponded to each other. The concentrations of 16 clinically available drugs determined by these two methods are shown in Table 1. As shown in Table 1, TACs at $7 \mathrm{n}$ of all drugs, except vinblastine and bleomycin, corresponded well with one-tenth of the PPC of each drug. In addition, TACs of vinblastine and bleomycin ranged, at maximum, within only 7-fold higher.

Association between Morphological Assay and FCM Assay Results The DNA integrities assessed by the FCM analysis were compared with the morphological changes of tumor cell nuclei. As shown in Table 2, good associations were observed between two methods; i.e., the true-positive rate was $96 \%(27 / 28)$, the true-negative rate $88 \%(136 / 154)$, and the overall accuracy $90 \%(163 / 182)$.

Antitumor Activities of TAS-103 and Other Investigational New Drugs against Surgical Specimens As shown in Tables 3 and 4 , TAS- 103 at $5 \mu \mathrm{g} / \mathrm{ml}(7 \mathrm{n})$ showed significantly higher effective rates (ERs) and definitely effective rates (DERs) than those of other new drugs at $7 \mathrm{n}$ against all of the tumors examined. TAS- 103 at $0.5 \mu \mathrm{g} / \mathrm{ml}(0.7 \mathrm{n})$ also showed the highest ERs among new drugs against the majority of tumors.

Antitumor Activities of Clinically Available Anticancer Agents and TAS-103 against Surgical Specimens As shown in Tables 3 and 4, aclarubicin showed the highest ERs and DERs against all of the tumors among topoisomerase inhibitors, and these activities are comparable to those of TAS103 at $5 \mu \mathrm{g} / \mathrm{ml}$. Mitomycin C, cytosine arabinoside and paclitaxel showed the highest ERs against the majority of tumors among antitumor antibiotics, antimetabolites and antimicrotuble agents, respectively. Among alkylating agents, several drugs (melphalan, cyclophosphamide, cisplatin and carboplatin) showed the highest ERs against, at least, one type of tumor. However, the ERs and DERs of all these drugs were significantly lower than those of TAS-103 at $5 \mu \mathrm{g} / \mathrm{ml}$. More-

Table 2. Association between Morphological Assay and Flow Cytometric Assay Results

\begin{tabular}{ccccc}
\hline \hline No. of drugs $^{a)}$ & $+/+^{b)}$ & $+/-$ & $-/+$ & $-/-$ \\
\hline 182 & 27 & 1 & 18 & 136
\end{tabular}

a) Six tests (5 glioblastoma multiforme and 1 adenocarcinoma of the lung) were done with a total of $182(56,34,26,12,12$ and 42 , respectively) anticancer drugs. $b)$ Flow cytometric assay/morphological assay; +, positive; -, negative. over, ERs of TAS-103 at $0.5 \mu \mathrm{g} / \mathrm{ml}$ against non-small cell lung cancer, bone and soft tissue sarcomas, breast cancer and small cell lung cancer were higher than those of the majority of clinically available anticancer agents.

\section{DISCUSSION}

We have developed the FCM assay as a drug sensitivity test on the basis of morphological changes of apoptotic nuclei. The assays based on morphological changes of the whole tumor cells were employed in the 1970s and the predictive accuracy was reported to be $50 \%{ }^{41)}$ However, a unique morphological method employed in the present study was shown to have the overall accuracy of $94 \%$ in ovarian cancer patients. ${ }^{14)}$ Supporting this, good associations were observed between results of the morphological assay and the FCM assay (Table 2).

Correlations between TAC and PPC were examined for 16 clinically available anticancer agents, and it was found that TACs at $7 \mathrm{n}$ of 14 drugs corresponded well with one-tenth of the PPC of each drug (Table 1). Moreover, a good correlation between the concentration of ranimustine (MCNU) estimated by the TAC method and the actual concentration in human brain tumors has been shown, ${ }^{42)}$ in which 6 patients with malignant gliomas or metastatic brain tumors had been given MCNU by one-shot intravenous injection at $150 \mathrm{mg} / \mathrm{body}$ $(2.34-3.75 \mathrm{mg} / \mathrm{kg}$; TAC, $3.04-4.88 \mu \mathrm{g} / \mathrm{ml})$, while the maximum concentration of MCNU in the tumor tissues has been found to be $2.38-3.31 \mu \mathrm{g} / \mathrm{g}$.

In the present study, with the FCM assay and the TAC method, the antitumor activity of TAS-103 was examined against fresh surgical specimens resected from 501 patients (8 types of tumors). As a result, TAS-103 at $5 \mu \mathrm{g} / \mathrm{ml}$ showed significantly higher ERs and DERs than those of all other investigational new drugs and all clinically available anticancer agents (except aclarubicin) against all the tumors examined (Tables 3, 4). Furthermore, TAS-103 at $0.5 \mu \mathrm{g} / \mathrm{ml}$ also showed excellent antitumor activities (Tables 3, 4).

TAS-103 was shown to have unique biological actions and high antitumor activities against murine and human tumors in vitro and in vivo. ${ }^{1)}$ In addition, it was also shown in the toxicological studies in cynomolgus monkeys that the doselimiting toxicity of TAS-103 given by single or intermittent (once per 3 weeks, 2 doses) administration was leukopenia and other toxicity to major organs was not observed. ${ }^{43}$ )

Aclarubicin showed the highest ERs and DERs against all of the tumors examined among topoisomerase inhibitors, and these activities are comparable to those of TAS-103 at $5 \mu \mathrm{g} / \mathrm{ml}$ (Tables 3, 4). It is interesting to note that aclarubicin is seemed to be a topo I and topo II inhibitor, ${ }^{44)}$ like TAS103. ${ }^{1)}$

A clinical phase I study of TAS-103 has been carried out against 32 patients; including 16 colorectal, 7 lung, and 5 head and neck. ${ }^{45)}$ TAS-103 was administered to patients as a continuous intravenous infusion over $1 \mathrm{~h}$. One dose of TAS103 (50 to $200 \mathrm{mg} / \mathrm{m}^{2}$ ) was given weekly for 3 weeks, repeated every $35 \mathrm{~d}$. The MTD was approximately $160 \mathrm{mg} / \mathrm{m}^{2}$ and the dose-limiting toxicity was neutropenia. The authors recommended a dose of 130 to $160 \mathrm{mg} / \mathrm{m}^{2}$, administered using the weekly schedule, for phase II studies. In the present study, based on the TAC method, a starting dose (n) of TAS- 


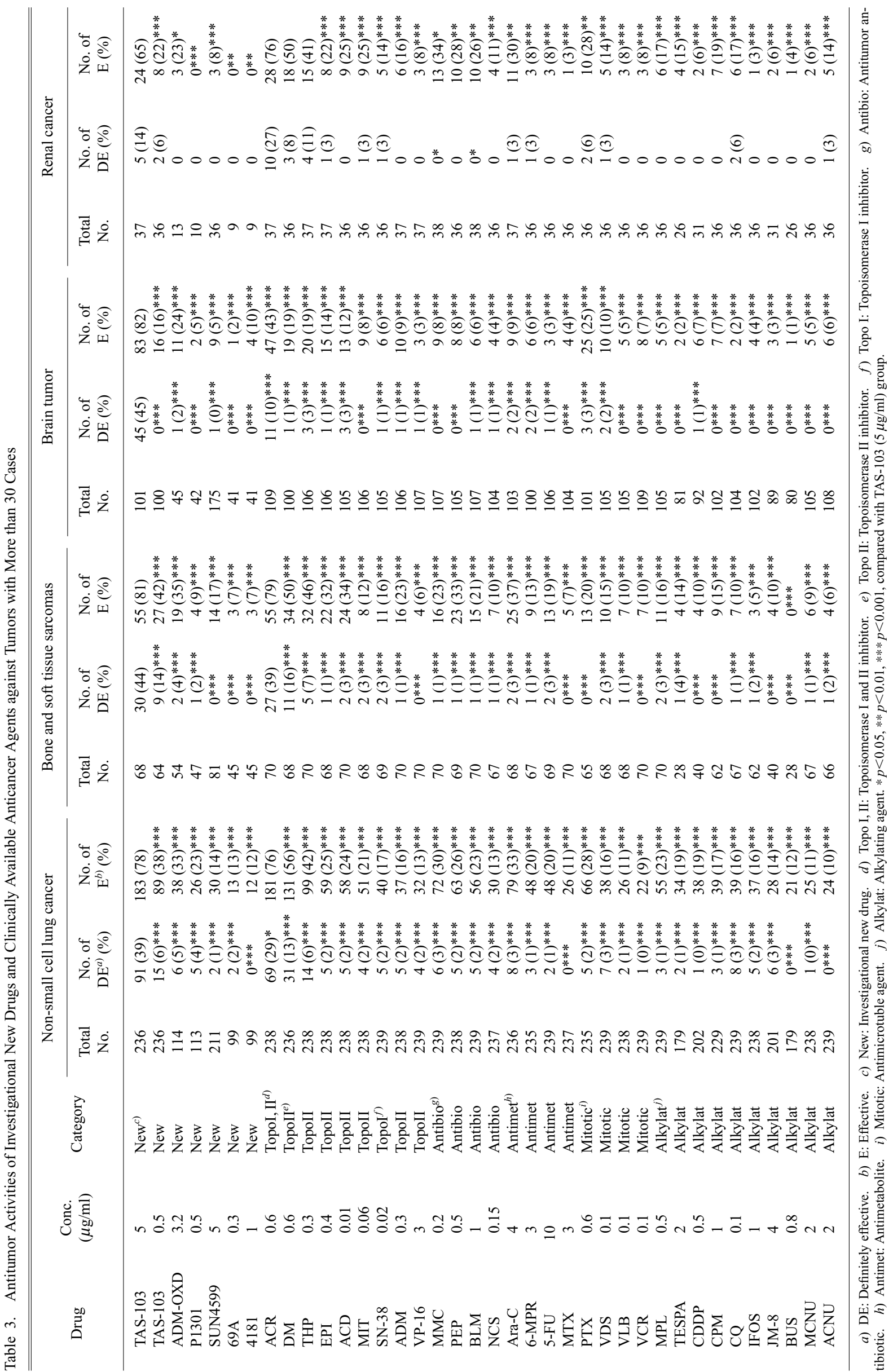




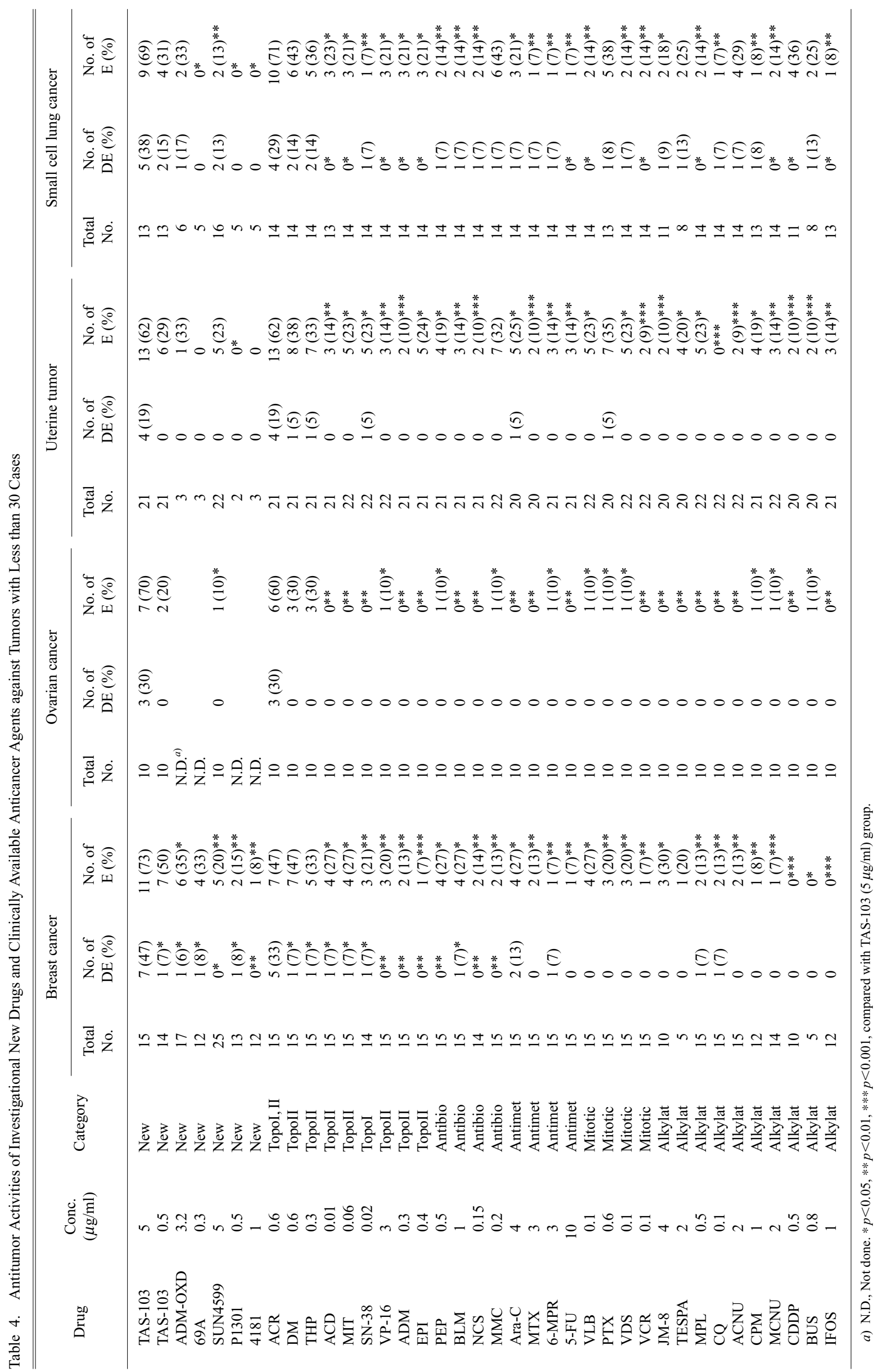


103 was estimated to be $20 \mathrm{mg} / \mathrm{m}^{2}$ and the MTD was expected to be $7 \mathrm{n}$ to $9 \mathrm{n}$ at the modified Fibonacci's dose-escalation scheme, ${ }^{37)} 140$ to $180 \mathrm{mg} / \mathrm{m}^{2}$. These results, together with the aforementioned results of a good correlation between the TAC and PPC of 14 clinically available anticancer drugs, suggest that the TAC method advanced by Schabel et $a l .{ }^{19)}$ can predict the optimal concentrations of the investigational new drugs which are employed in the in vitro chemosensitivity test.

However, it was shown in this clinical study that the PPCs of TAS-103 after intravenous administration of 130, 160 and $200 \mathrm{mg} / \mathrm{m}^{2}$ were 1.5 to $2.2 \mu \mathrm{g} / \mathrm{ml}$, not $50 \mu \mathrm{g} / \mathrm{ml}$, and high protein binding of this drug was speculated to concern. ${ }^{45)}$ It is interesting to know whether TAS-103 may attain to the concentration of $50 \mu \mathrm{g} / \mathrm{ml}$ and show any significant antitumor activity when given on another treatment schedule (for example, one-shot intravenous injection). Furthermore, development of a new drug delivery system of TAS-103, such as encapsulation into liposome, ${ }^{46}$ may give a possibility that TAS-103 shows its inherent promising antitumor activities against a wide range of human tumors.

Acknowledgments The author thanks Dr. Hideki Kimura (Dept. of Thoracic Diseases), Dr. Katsunobu Osato (Dept. of Neurological Surgery), Dr. Shin-ichiro Tatezaki (Dept. of Orthopedic Surgery), Dr. Masahira Hirono (Dept. of Gynecology) and Dr. Masayuki Maruoka (Dept. of Urology), Chiba Cancer Center Hospital, and Dr. Yasuo Iwadate, Dept. of Neurosurgery, Chiba University School of Medicine, for offering a chance to perform the chemosensitivity tests against 525 surgical specimens. The author thanks Taiho Pharmaceutical Co. (Saitama, Japan) for providing TAS-103, 4181 and 69A, Suntory Ltd. (Tokyo, Japan) for SUN-4599, Green Cross Corporation (Osaka, Japan) for ADM-OXD, Daikin Industries, Ltd. (Osaka, Japan) for P1301, Shionogi \& Co., Ltd. (Osaka, Japan) for 4-hydroperoxycyclophosphamide and 4-hydroperoxyifosfamide, and Yakult Honsha Co. (Tokyo, Japan) for SN-38. The author appreciates National Cancer Institute and Cancer Chemotherapy Center, Japanese Foundation for Cancer Research, for the supply of animals and giving a chance for carrying out the toxicological study. The author thanks Junko Inada and Hatsumi Onoda for technical assistance.

\section{REFERENCES}

1) Utsugi T., Aoyagi K., Asao T., Okazaki S., Aoyagi Y., Sano M., Wierzba K., Yamada Y., Jpn. J. Cancer Res., 88, 992-1002 (1997).

2) Hamburger A. W., Salmon S. E., Science, 197, $461-463$ (1977).

3) Mosmann T., J. Immunol. Methods, 65, 55-63 (1983).

4) Tanigawa N., Kern D. H., Hikasa Y., Morton D. L., Cancer Res., 42, 2159-2164 (1982).

5) Tokita H., Tanaka N., Ueno T., Fujimoto S., Sekiya S., Takamizawa H., Jpn. J. Cancer Clin., 34, 1101-1105 (1988).

6) Kangas L., Gronroos M., Nieminen A. L., Med. Biol., 62, 338-343 (1984).

7) Furukawa T., Kubota T., Watanabe M., Takahara T., Yamaguchi H., Takeuchi T., Kase S., Kodaira S., Ishibiki K., Kitajima M., Int. J. Cancer, 51, 489-498 (1992).

8) Salmon S. E., Hamburger A. W., Soehnlen B., Durie B. G., Alberts D. S., Moon T. E., N. Engl. J. Med., 298, 1321-1327 (1978).

9) Alonso K., Cancer, 54, 2475-2479 (1984).

10) Mattern J., Volm M., Cancer Treat. Rev., 9, 267-298 (1982).

11) Iwadate Y., Fujimoto S., Sueyoshi K., Namba H., Tagawa M., Yama- mura A., Neurosurgery, 40, 782-788 (1997).

12) Nicoletti I., Migliorati G., Pagliacci M. C., Grignani F., Riccardi C., J. Immunol. Methods, 139, 271-279 (1991).

13) Darzynkiewicz Z., Bruno S., Del Bino G., Gorczyca W., Hotz M. A., Lassota P., Traganos F., Cytometry, 13, 389-394 (1992).

14) Sekiya S., Iijima N., Oosaki T., Takamizawa H., Tokita H., Gynecol. Oncol., 40, 138-143 (1991)

15) Iwadate Y., Fujimoto S., Yamaura A., Int. J. Mol. Med., 10, 187-192 (2002).

16) Iwadate Y., Fujimoto S., Namba H., Yamaura A., Br. J. Cancer, 89, 1896 - 1900 (2003).

17) Von Hoff D. D., Casper J., Bradley E., Sandbach J., Jones D., Makuch R., Am. J. Med., 70, 1027-1032 (1981).

18) Von Hoff D. D., Clark G. M., Stogdill B. J., Sarosdy M. F., O’Brien M. T., Casper J. T., Mattox D. E., Page C. P., Cruz A. B., Sandbach J. F., Cancer Res., 43, 1926-1931 (1983).

19) Schabel F. M., Jr., Skipper H. E., Trader M. W., Wilcox W. S., Cancer Chemother. Rep., 48, 17-30 (1965).

20) Alberts D. S., Chen H. S. G., "Cloning of Human Tumor Stem Cells," ed. by Salmon S. E., Alan R. Liss, New York, 1980, pp. 351-359.

21) Hisaoka M., Morioka T., Yagita A., Jpn. J. Cancer Res. (Gann), 73, $161-166$ (1982).

22) Yasui Y., Suzumori K., Yagami Y., Jpn. J. Cancer Clin., 34, 19751978 (1988).

23) Mori T., Mineura K., Katakura R., Brain and Nerve, 31, 601-606 (1979).

24) Stewart J. A., McCormack J. J., Krakoff I. H., Cancer Treat. Rep., 66, 1327-1331 (1982).

25) Ehrsson H., Hassan M., Ehrnebo M., Beran M., Clin. Pharmacol. Ther, 34, 86-89 (1983).

26) Chan K. K., Hong P. S., Tutsch K., Trump D. L., Cancer Res., 54, $6421-6429$ (1994).

27) Kurowski V., Wagner T., Cancer Chemother. Pharmacol., 33, 36- 42 (1993).

28) Bateman J. C., Carlton H. N., Calvert R. C., Lindenblad G. E., Int. J. Appl. Radiat. Isot., 7, 287-298 (1960).

29) Gaver R. C., Colombo N., Green M. D., George A. M., Deeb G., Morris A. D., Canetta R. M., Speyer J. L., Farmen R. H., Muggia F. M., Cancer Chemother. Pharmacol., 22, 263-270 (1988).

30) Gianni L., Kearns C. M., Giani A., Capri G., Vigano L., Lacatelli A., Bonadonna G., Egorin M. J., J. Clin. Oncol., 13, 180-190 (1995).

31) Otsuka T., Matsukado Y., Uemura S., Kuratsu J., Sonoda H., Mihara Y., Goto S., Neurol. Med. Chir. (Tokyo), 29, 471-475 (1989).

32) Robert J., David M., Huet S., Chauvergne J., J. Cancer Clin. Oncol., 24, 1289-1294 (1988).

33) Camaggi C. M., Comparsi R., Strocchi E., Testoni F., Angelelli B., Pannuti F., Cancer Chemother. Pharmacol., 21, 221-228 (1988).

34) Ando S., Nakamura T., Kagawa D., Ueda T., Nishimura T., Kubo A., Tsutani H., Sasada M., Uchino H., Cancer Treat. Rep., 70, 835-841 (1986).

35) Masuda N., Fukuoka M., Kudoh S., Kusunoki Y., Matsui K., Nakagawa K., Hirashima T., Tamanoi M., Nitta T., Yana T., J. Clin. Oncol., 12, 90-96 (1994).

36) Freireich E. J., Gehan E. A., Rall D. P., Schmidt L. H., Skipper H. E., Cancer Chemother. Rep., 50, 219-244 (1966).

37) Goldsmith M. A., Slavik M., Carter S. K., Cancer Res., 35, 1354 1364 (1975).

38) Natsume T., Kobayashi M., Fujimoto S., Cancer, 92, 386-394 (2001).

39) Fujimoto S., Jpn. J. Cancer Digestive Organs, 6, 521-529 (1996).

40) Bakowski M. T., Crouch J. C., Cancer Treat. Rev., 10, 159-172 (1983).

41) Wright J. C., Walker D. A., J. Surg. Oncol., 7, 381-392 (1975).

42) Harada K., Kiya K., Kobayashi M., Takeda T., Mukada K., Hozumi T., Jpn. J. Cancer Chemother, 8, 735-742 (1981).

43) Utsugi T., Aoyagi K., Furune Y., Sano M., Wierzba K., Okazaki S., Asao T., Yamada Y., Proc. Am. Assoc. Cancer Res., 37, 2915 (1996).

44) Bridewell D. J., Finlay G. J., Baguley B. C., Oncol. Res., 9, 535-542 (1997).

45) Ewesuedo R. B., Iyer L., Das S., Koenig A., Mani S., Vogelzang N. J., Schilsky R. L., Brenckman W., Ratain M. J., J. Clin. Oncol., 19, 2084-2090 (2001).

46) Shimizu K., Takada M., Asai T., Kuromi K., Baba K., Oku N., Biol. Pharm. Bull., 25, 1385-1387 (2002). 